\title{
Causes of Acute Peritonitis and its Outcome in Tertiary Medical Centre
}

\author{
Mariam Malik, Mazhar Iqbal, Abdul Malik Magsi, Sughra Parveen, Muhammad Iqbal Khan, \\ Munazza Shamim, Shoaib Malik
}

\begin{abstract}
OBJECTIVE: To determine the factors causing peritonitis and deaths at Jinnah Hospital Karachi.

METHODOLOGY: The study included 216 patients with acute peritonitis who underwent exploratory laparotomy from 2016 to 2018. Surgical treatment according to cause and post-operative treatment of disease carried out. Histopathological report and other diagnostic test like typhoid dot test and blood culture results were recorded and resultwas analyzed by SPSS version 24.
\end{abstract}

RESULTS: Frequent causes of acute peritonitis were typhoid intestinal perforation $62(28.70 \%)$,Peptic ulcer perforation $54(25 \%)$, rupture appendix $38(17.59 \%)$, tuberculous intestine perforation $26(12.05 \%)$, gangrene gut $14(6.48 \%)$, large gut tumor perforation $10(4.62 \%)$, ruptured liver abscess $4(1.85 \%)$, ruptured gall balder $4(1.85 \%)$ and acute pancreatitis $4(1.85 \%)$. Complications were septic shock 30 (13.88\%), paralytic ileus $16(7.40 \%)$, burst abdomen $12(5.5 \%)$ and mortality was $8(3.70 \%$.)

CONCLUSION: Infectious diseases like typhoid, H-pylori PUD, ruptured appendix, ruptured liver abscess, and TB intestine are common causes of peritonitis.

KEY WORDS: Perforation peritonitis, Typhoid lleal perforation, Duodenal ulcer perforation.

This article may be cited as: Malik M, Iqbal M, Magsi AM, Parveen S, Khan MI, Shamim M, Malik S. Causes of Acute Peritonitis and its Outcome in Tertiary Medical Centre. J Liaquat Uni Med Health Sci. 2019;18(03):193-6. doi: 10.22442/jlumhs.191830626

\section{INTRODUCTION}

Inflammation of peritoneum covering inner wall of abdomen and organs is called peritonitis. The causes can include trauma, colonoscopy, and bowel obstruction such as volvulus, colon cancers, diverticulitis, stomach ulcers, ischemic bowel and infection like clostridium difficile. Hole in bowel can allow bacteria to enter into peritoneal cavity and hole in stomach lead to chemical peritonitis. A CT scan is preferred method for diagnosis, however free air can be seen on plain X-ray.

Risk of death is up to $50 \%$. Complications are affected by old age and comorbidities. Causes of peritonitis also affect the prognosis. Complication like septicemia, wound abscess, reaction to anesthetic drugs and other drugs like antibiotic makes the prognosis worse. Other complications like tertiary peritonitis, wound dehiscence, surgical site infection, entero-cutaneous fistula, abdominal compartment syndrome and respiratory insufficiency can occur. Entero-cutaneous fistula leads to volume, protein and electrolyte losses. Peritonitis stops the movement of bowel causing paralytic ileus. Intestinal perforation is dreaded and common complications of typhoid fever causing diffuse peritonitis despite to new antibiotics. We all now see increasing numbers of ileal perforation even multiple perforations ${ }^{1}$. Prevalence of typhoid fever is gradually decreasing worldwide but still endemic in Indian subcontinent. Intestinal hemorrhage is also common due to typhoid and is most frequent cause of mortality and morbidity ${ }^{2}$. Mortality in typhoid perforation is reported to be between 5 to $62 \%{ }^{2}$. Fecal fistula is the most common complication occur often due to an anastomotic leak or re-perforation. Tuberculosis of ileum and rupture of appendix frequently cause peritonitis which can be prevented, if diagnosed and treated early.

Rational of study was that, in our population still infections like typhoid, TB and ruptured appendix are causing peritonitis and deaths. To know the exact frequency of these patients having peritonitis related deaths so measures may be taken to prevent the peritonitis by giving awareness of diseases which can be beneficial for community.

Objective of study is to find out the causes of acute peritonitis, its mortality and morbidity in our population.

\section{METHODOLOGY}

This observational descriptive study was conducted in Ward 3, JPMC from October 2016 to October 2018. Patients of above 12 years of age both male and female were included. All patients presented in 
emergency department with complaints of abdominal pain, vomiting, constipation and on examination generalized tenderness of abdomen, absent gut sounds and air under diaphragm in plain X-ray were diagnosed as acute peritonitis. Exploratory laparotomy was done. Operative finding like duodenal perforation, ileal perforation, stricture of ileum with perforation, ruptured appendix, ruptured liver abscess, pancreatic necrosis, tumor of large gut perforation and gangrenous gut were recorded on Performa. Tissues from margins of perforation, lymph nodes, and omental biopsies were taken for histopathological examination as well as typhidot and blood culture were performed postoperatively in suspected typhoid fever. lleostomy was made in typhoid perforation and TB intestine perforation when patient presented after 48 hours of peritonitis or presented in shock. Primary repair of gut is done in early presentation of ileal perforation within 48 hours. Postoperatively causes of perforation were treated and complications of acute peritonitis like organ failure, peritoneal abscess, paralytic ileus, burst abdomen and surgical site infection were recorded. Complication related to comorbidity and ileostomy were excluded. All patients of peritonitis due to trauma and peritonitis and due to anastomotic leak were excluded from the study. Mortality related to peritonitis were also recorded. Frequency of causes of peritonitis and mortality were analyzed by SPSS version 24.0.

\section{RESULTS}

There were 216 patients diagnosed as acute peritonitis, 160 were male $(74.07 \%)$ and $56(25.93 \%)$ were female. Age range was between 12 to 65 years. About 13 to 20 years of age patients were 68 (31.48\%), 21 to 40 years were $86(39.81 \%), 41$ to 60 years of age were $56(25.92 \%)$ and above 61 year of age were $6(2.77 \%)$.

TABLE I: CAUSES OF ACUTE PERITONITIS

\begin{tabular}{|l|c|c|c|}
\hline \multicolumn{1}{|c|}{ Causes } & $\begin{array}{c}\text { No. of } \\
\text { Patients }\end{array}$ & $\begin{array}{c}\text { Total } \\
\text { Patients }\end{array}$ & Percentage \\
\hline Typhoid Ileal Perforation & 62 & 216 & 28.70 \\
\hline Duodenal Perforation & 54 & 216 & 25.00 \\
\hline Ruptured Appendix & 38 & 216 & 17.59 \\
\hline Tb Intestine Perforation & 26 & 216 & 12.03 \\
\hline Gangrenous Gut & 14 & 216 & 6.48 \\
\hline Tumor Perforation & 10 & 216 & 4.62 \\
\hline Ruptured Liver Abscess & 04 & 216 & 1.85 \\
\hline $\begin{array}{l}\text { Gangrenous Gall } \\
\text { Bladder }\end{array}$ & 04 & 216 & 1.85 \\
\hline Acute Pancreatitis & 04 & 216 & 1.85 \\
\hline
\end{tabular}

Majority of patient of acute peritonitis belonged between 21 to 40 years of age and males were involved predominantly. One hundred and forty-two patients $(65.73 \%)$ developed perforation of gut due to duodenal ulcer, typhoid enteritis and TB intestine. Forty two patients (19.44\%) developed peritonitis was due to rupture of appendix and liver abscess. Eight patients died during study, in which Four patients were of intestinal TB, one of tumor perforation of large gut, One due to duodenal perforation and Two of typhoid ileal perforation, all patients died were presented in septic shock and came in emergency 3 to 5 days after developing peritonitis. One Hundred twenty eight patients $(59.25 \%)$ recovered uneventful and eighty eight patients $(40.75 \%)$ developed complication.

\section{TABLE II:}

COMPLICATIONS OF ACUTE PERITONITIS

\begin{tabular}{|l|c|c|c|}
\hline \multicolumn{1}{|c|}{ Complications } & $\begin{array}{c}\text { No. of } \\
\text { Patients }\end{array}$ & $\begin{array}{c}\text { Total } \\
\text { Patients }\end{array}$ & Percentage \\
\hline Uneventful Recovery & 128 & 216 & 59.25 \\
\hline $\begin{array}{l}\text { Septicemia \& Organ } \\
\text { Failure }\end{array}$ & 30 & 216 & 13.80 \\
\hline Paralytic lleus & 16 & 216 & 7.40 \\
\hline Burst Abdomen & 12 & 216 & 5.55 \\
\hline Mortality & 08 & 216 & 3.70 \\
\hline Leakage of Anastomosis & 01 & 216 & 0.46 \\
\hline
\end{tabular}

\section{DISCUSSION}

Peritonitis is a most common surgical emergency all over the world and in Pakistan as well. TB intestine, typhoid fever and duodenal ulcer perforation are common-- culprit in our society due to contaminated water. These diseases can be prevented at greater extent by using clean water and frequency of peritonitis can be decreased. Mortality due to peritonitis can be decreased. Spectrum of causes of peritonitis is different from western counter part because these diseases are almost eradicated in western world.

In our study, peritonitis was common due to perforation in upper part of GIT due to infection where in western part perforation is common in lower parts of GIT due to carcinoma ${ }^{3}$.

The most common cause of acute peritonitis noted in other study was (45\%) perforated peptic ulcer with duodenal ulcer $(43.6 \%)$ and gastric ulcer $(1.3 \%)$. The small bowel tuberculosis perforation $(21 \%)$, typhoid perforation (17\%), TB perforation $(2.6 \%)$, malignancy $(2.6 \%)$, rupture appendix $(5 \%)$, volvulus $(3 \%)$ and overall mortality was $(10.6 \%)^{4}$.

In our study common causes of acute peritonitis were typhoid ileal perforation (28.70\%), the duodenal ulcer 
perforation (25\%)the rupture appendix (17.59\%),TB intestine $(12.03 \%)$ and mortality in this study is less $(3.70 \%)$ as compared to study conducted in Pakistan by Afridi SP $2008^{4}(10.6 \%)$.

Causes of perforation in Pakistan is different from western countries where large gut perforation due to colorectal cancer is most common frequency of silent perforation of duodenal ulcer is $77.27 \%$ and $\mathrm{H}$-pylori infection was present in $77.77 \%{ }^{5}$. Intestinal tuberculosis causing obstruction and perforation are common in female patients ${ }^{6}$, and female were predominantly involved in intestinal TB.

In our study predominantly involved patients were male. Study conducted in civil hospital Karachi predominantly females were involved but another study was conducted in India in which males were involved predominantly ${ }^{7}$ and duodenal perforation was leading cause $(63 \%)$ and ileum only in $(10 \%)$. In another study duodenal perforation was $46 \%$, ileum perforation $32 \%$, perforated appendix $6.4 \%$, gallbladder perforation $5.3 \%$ and mortality rate was very high $(59 \%)^{8}$. These findings are quite different from our study and mortality in other study was $12.63 \%$, occurred more in patients presented late in septic shock ${ }^{9}$. Our study showed low mortality (3.7\%) which may be due to early presentation and age group of the patients was relatively young, and our results show that $70 \%$ of the patients had pneumoperitoneum on chest $x$-ray. Study conducted in India by Bali RS $2014^{10}$ shows pneumoperitoneum was present in $79 \%$.

Infection is most common cause of perforation peritonitis ${ }^{11}$. Perforation in Pakistan has different spectrum as compared to western countries. Typhoid perforation as per the study is the leading cause than peptic ulcer perforation which is usually due to contaminated water. Early surgical intervention have decreased the mortality, if eradication of $\mathrm{H}$. pylori by triple therapy and make early diagnosis of typhoid and treat it with appropriate antibiotics then peritonitis can be significantly prevented, so early treatment of these diseases and use of boiled water by community can reduce incidence of peritonitis due to typhoid and $\mathrm{H}$. pylori infection peptic ulcer perforation.

Duodenal perforation is mainly due to $\mathrm{H}$. Pylori $(77 \%)^{5}$ and occurred commonly in low socioeconomic group who cannot buy mineral water, But low socioeconomic group can use boiled water to prevent perforation leading to peritonitis and physicians must diagnose early and properly treat $\mathrm{H}$. pylori infections.

Typhoid fever in our study was the leading cause of perforation of gut $(28.70 \%)$ as compared to studies conducted by Garg RK $2016^{9}$, Bali RS $2014^{10}$ and Khana AK $1984^{11}$ where peptic ulcer was leading cause, most probably reason is unhygienic conditions and use of contaminated water.

Ruptured appendix is third common cause in this study $(17.59 \%)$ in another study by Batra $\mathrm{P} 2013^{12}$ it was $3.82 \%$ and $24 \%$ in India by Sarkar S $2018^{7}$.

Early surgical intervention with 6 hours along with broad spectrum antibiotics proceeded by aggressive resuscitation improved outcome of peritonitis ${ }^{13}$. Our low mortality was also due to same reasons.

Tuberculous intestine is usually causing intestinal obstruction but can cause perforation of gut leading to peritonitis. In study $12.03 \%$ presented with TB. Intestine causing peritonitis. It was also found in India i-e; $6 \%$ of the patients ${ }^{7}$ but a western world TB is not cause of perforation.

Gangrenous gut due to volvulus $(6.48 \%)$, ruptured liver abscess $(1.85 \%)$ and generalized peritonitis due to necrotizing pancreatic $(1.85 \%)$ were less common causes. In present study same result were found in the other studies as well ${ }^{9-11}$. Gall bladder perforation was rare cause of perforation peritonitis in elderly patients due to empyema gallbladder $(1.85 \%)$. In another study gall bladder perforation was found in $5.3 \%^{8}$.

In our study there was no complication noted in $59.25 \%$ and post-operative complications occurred in $40.75 \%$, as septic shock $(13.88 \%)$, paralytic ileus $(7.40 \%)$, burst abdomen $(5.55 \%)$ and death $(3.70 \%)$ The rate of complication in study by Batra P $2013^{12}$ was $26.25 \%$, mortality was $5.7 \%$. Mortality in two other studies by Malhotra MK $2016^{8}$ and Garg RK $2016^{9}$ was $11.8 \%$ and $12.63 \%$ respectively. Good post -operative care can reduce the complication.

Limitation of this study was exclusion of children which can slightly affect the result.

\section{CONCLUSION}

Infectious diseases like typhoid, TB and H. pylori causing duodenal ulcer perforation are major cause of peritonitis, which can be prevented by using the boiled drinking water and complication of peritonitis can be minimized by early surgical intervention.

Ethical permission: This study was approved by the Ethics Committee of Jinnah Postgraduate Medical Center, Karachi. No. F.2-81/2018-GENL/2255/JPMC Dated 01-06-2018.

Conflict of Interest: The authors declare no conflicts of interest regarding this study.

\section{Funding: None}

\section{REFERENCES}

1. Sharma AK, Sharma RK, Sharma SK, Sharma A, Soni D. Typhoid Intestinal Perforation: 24 Perforations in One Patient. Ann Med Health Sci Res. 2013; 3(Suppl 1): S41-S43. 
doi: 10.4103/2141-9248.121220.

2. Saxe JM, Cropsey R. Is operative management effective in treatment of perforated typhoid? Am J Surg. 2005; 189(3): 342-4.

3. Atamanalp SS, Aydinli B, Ozturk G, Oren D, Basuglu M, Yildirgan MI. Typhoid Intestinal Perforations: twenty-six year experience. World J Surg. 2007; 31(9): 1883-8.

4. Afridi SP, Malik F, Ur-Rahman S, Shamim S, Samo KA. Spectrum of perforation peritonitis in Pakistan: 300 cases Eastern experience. World J Emerg Surg. 2008; 3: 31. doi: 10.1186/1749-7922 -3-31.

5. Magsi AM, lqbal M, Malik M, Parveen S. Silent peptic ulcer disease perforation. J Surg Pakistan. 2017; 22(2): 61-64. doi:10.21699/jsp.22.2.7.

6. Khan MI, Ali MS, Khan I, Iqbal M, Parveen S, Shah SH. Tuberculosis of intestine. J Surg Pakistan. 2016; 21(2): 75-8. doi:10.21699/ jsp.21.2.9

7. Sarkar S, Prasad C, Mukherjee D. A study to highlight the spectrum of perforation peritonitis and its outcome in tertiary rural medical center. PARIPEX-Indian J Res. 2018; 7(2): 7-8.

8. Malhotra MK, Singal R, Chowdhary K, Sharma
RG. Spectrum of perforation peritonitis in a Rural Medical College. Bangladesh J Med Sci. 2016; 15: 70-73. doi:10.3329/bjms.v15i1.20857.

9. Garg RK, Gupta R, Kailasia Y, Chhari AS, Jain M, Dubey C. Spectrum of nontraumatic perforation peritonitis: a prospective study of 277 cases with special reference to morbidity and mortality. Int Surg J. 2016; 3(3): 1223-8. doi:10.18203/23492902.isj20161435.

10. Bali RS, Verma S, Agarwal PN, Singh R, Talwar N. Perforation Peritonitis and the Developing World. ISRN Surgery. 2014;105492: 1-4. doi:10.1155/2014/105492.

11. Khana AK, Misra MK. Typhoid perforation of the gut. PostGrad Med J. 1984; 60(706): 523-25. doi:10.1136/ pgmj.60.706.523.

12. Batra P, Gupta D, Narang R. Spectrum Of Gastro Intestinal Perforation Peritonitis In Rural Central India. J Mahatma Gandhi Inst Med Sci. 2013; 18 (1): 44-8.

13. Bhandari TR, Poudel R, Chandra K. Effect of early surgery on outcome in perforation peritonitis. J Univ Coll Med Sci. 2017; 5(1): 12-16. doi:10.3126/jucms.v5i1.19048.

\section{AUTHOR AFFILIATION: \\ Dr. Mariam Malik \\ Resident, Department of Surgery \\ Jinnah Postgraduate Medical Centre \\ (JPMC), Karachi, Sindh-Pakistan. \\ Dr. Mazhar Iqbal \\ Associate Professor, Department of Surgery \\ JPMC, Karachi, Sindh-Pakistan. \\ Dr. Abdul Malik Magsi (Corresponding Author) \\ Resident, Department of Surgery \\ JPMC, Karachi, Sindh-Pakistan. \\ Email: malik.magsi@hotmail.com] \\ Dr. Sughra Parveen \\ Professor, Department of Surgery \\ JPMC, Karachi, Sindh-Pakistan. \\ Dr. Muhammad Iqbal Khan \\ Professor, Department of Surgery \\ JPMC, Karachi, Sindh-Pakistan. \\ Dr. Munazza Shamim \\ Resident, Department of Surgery \\ JPMC, Karachi, Sindh-Pakistan. \\ Dr. Shoaib Malik \\ Assistant Professor, Department of Anesthesiology \\ JPMC, Karachi, Sindh-Pakistan.}

